\title{
DANÇA, MEIO AMBIENTE E CULTURA: A VIVÊNCIA DO POVO SATERÉ MAWÉ NA ÁREA URBANA DE MANAUS
}

\author{
Thelma Lima da C. Marreiro ${ }^{1}$
}

Doriedson de Oliveira Santos ${ }^{2}$

Alyne França Góes ${ }^{3}$

\begin{abstract}
RESUMO: Este projeto de pesquisa teve como objetivo Compreender o ritual da Tucandeira como manifestação artístico-cultural dos Sateré-Mawé na comunidade Yapyrehyt, e estudou a temática, dança, meio ambiente e cultura da comunidade Sateré-Mawé Y'Apyrehyt, no bairro de Redenção na cidade de Manaus, buscando compreender e valorizar a cultura e seus costumes. A pesquisa foi desenvolvida numa abordagem qualitativa, etnográfica, metodológica, e um registro áudio visual e entrevista por meio do diálogo informal, focando o povo Sateré recidente na área urbana de Manaus, onde o povo Sateré-Mawé vive numa área verde tendo que se adaptar ao ritmo acelerado da cidade. Os sujeitos da pesquisa foram o tuxaua (Moisés Sateré, depois substituído pelo tuxaua Nilson Sateré) e os moradores da comunidade Y'apyrehyty, na cidade de Manaus. Para tanto foram realizadas visitas ao barracão da comunidade Y'apyrehyty durante o processo do trabalho de campo da pesquisa, em Manaus. A história, tradição e cultura do Sateré-Mawé têm sido relatadas oralmente, através de narrativas contadas pelos sábios, que explicam seus conhecimentos culturais transmitidos de geração a geração. $\mathrm{Na}$ contemporaneidade é responsabilidade dos jovens cultivarem esses saberes a fim de fortalecer e valorizar as práticas sociais da vida cotidiana e as manifestações artístico-culturais do Povo Sateré-Mawé no futuro.
\end{abstract}

Palavras-Chaves: Dança; Cultura; Meio Ambiente.

\footnotetext{
${ }^{1}$ Mestre em Educação e em Sociedade e Cultura na Amazônia na Universidade Federal do Amazonas. Doutoranda em Antropologia Social e Cultural na Universidade de Coimbra. Orientadora do Programa de Iniciação Científica - PAIC/ e da Fundação de Amparo e Apoio à Pesquisa no Amazonas - FAPEAM.

${ }_{2}$ Graduado em Pedagogia (UEA), Pós-Graduado em Metodologia do Ensino Superior (GAMA FILHO), Professor na Secretaria Municipal de Educação (SEMED). - E-Mail: doriedson_santos@yahoo.com.br.

${ }^{3}$ Acadêmica do 5o. Período de Dança. Bolsista do Programa de Iniciação Científica - PAIC e da Fundação de Amparo e Apoio à Pesquisa no Amazonas - FAPEAM.
} 


\section{INTRODUÇÃO}

Segundo as fontes documentais o povo indígena Sateré-Mawé, teve o primeiro contato com os nãos indígenas em 1661, e de forma mais intensa a partir de 1669, por meio do Padre João Maria, com a fundação da Missão Tupinambarana Jesuíta. E mantém até hoje suas tradições viva como a dança do Ritual da Tucandeira.

Tal ritual é realizado anualmente pelo Povo Sateré-mawé, inclusive na comunidade Yapyrehyt, em Manaus, local do trabalho de campo desta pesquisa, esse ritual é realizado por ocasião da semana dos povos indígenas e em outros momentos especiais, em que as famílias indígenas se reúnem para praticar o ritual e fazer assembleias para discutir assuntos de seus interesses.

O contato com outras culturas tem causado mudanças em sua maneira de viver. Segundo relatos das famílias Sateré-Mawé da comunidade Y'apyrehyt, localizada no bairro da Redenção, Zona Centro-Oeste de Manaus, eles sentiram essa mudança a partir do deslocamento da área indígena do rio Andirá em Maués para cidade Manaus, no fim da década de 1960 e início de 1970.

Esse deslocamento ocorreu devido às necessidades básicas sentidas nos atendimentos sociais como a falta de assistência a saúde e a educação por parte da Fundação Nacional do Índio - FUNAI. Tais direitos são assegurados pela Constituição Federal de 1988 nos artigos 231 e 232, porém parcialmente efetivados. Estar vivem em áreas urbanas não significa o rompimento de sua cultura ou de suas características culturais, mas buscar melhoria nos processos de territorialização, reivindicando das políticas públicas a implantação dos direitos coletivos conquistados e o reconhecimento da diversidade de saberes na área urbana, garantidos nas legislações nacionais e internacionais.

\subsection{A MUDANÇA DO AMBIENTE TRADICIONAL INDÍGENA PARA AS ÁREAS URBANAS}

Diversos fatores contribuíram para que os jovens saíssem de suas comunidades da área indígena do Rio Andirá e viessem para a cidade, com o objetivo de estudar e 
trabalhar. Mas chegando a capital encontraram muitas dificuldades para atingir seus objetivos, como discriminação, dificuldade de falar a língua portuguesa e adaptar-se ao modo de trabalho.

O projeto de pesquisa compreendeu os saberes indígenas do Povo Sateré-Mawé na zona urbana da cidade de Manaus, utilizou como referência o ritual da Tucandeira, com vistas a compreensão das manifestações artístico-culturais para a valorização dos saberes tradicionais da comunidade Sateré-Mawé Yapyrehyt.

Esta proposta fortaleceu também na atuação da Universidade do Estado do Amazonas com a participação do curso de dança na troca de experiências com os indígenas, que proporcionou um diálogo entre a linguagem artística contemporânea e a dança tradicional indígena do Ritual da Tucandeira.

A proposta artística deste projeto foi tomar como subsídio as práticas artísticoculturais do Povo Sateré-Mawé, como os seus rituais, ritmos e estilos tradicionais para perceber o mister que engloba esta parcela do universo da comunidade indígena, como elemento integrador na produção criativa na área da dança.

Este projeto de pesquisa fez referência a valorização da cultura e dança tradicional dos Sateré-Mawé, ao chegarem à área urbana, levando em consideração a tradição da dança da tucandeira, no processo de desenvolvimento da vida de um jovem ao entrar em fase adulta, superando assim seus desafios e enfrentando os padrões de uma vida totalmente diferenciada na cidade.

Assim, o registro do ritual do povo Sateré-Mawé, contextualiza a sua essência e mesmo morando em seu território tradicional ou não, ainda mantém os seus valores tradicionais e valorizam as práticas indígenas. Valorizar a produção artística do ritual da Tucandeira é reconhecer seus valores culturais mesmo permanecendo em uma sociedade diferente.

\section{METODOLOGIA}

A proposta teórico-metodológica foi desenvolvida numa abordagem qualitativa com a perspectiva da pesquisa participante no qual o grupo social pesquisado foi sujeito da investigação, valorizando seu conhecimento a fim de maior compreensão do fenômeno 
social, no contexto cultural não-indígena, na comunidade Sateré-Mawé Y'apyrehyt, localizada no bairro da Redenção, Zona Centro-Oeste da cidade de Manaus.

Foram compreendidas as características artístico-culturais dos sujeitos em estudo como protagonistas do conhecimento, a fim de possibilitar a percepção da relação entre a transmissão dos conhecimentos tradicionais indígenas.

\subsection{O MÉTODO}

No processo investigativo foi usado o método etnográfico em que a produção do conhecimento baseia-se na descrição densa do trabalho de campo e das características socioculturais do contexto da comunidade.

\section{2 ÁREA DE ESTUDO}

A área de atuação da pesquisa foi delimitada na comunidade Sateré-Mawé Yapyrehyt localizada no bairro da Redenção, Zona Centro-Oeste da cidade de Manaus, a comunidade surgiu por volta de 1970, sob a influência do ciclo da borracha e a exploração de sua terras na liderança de uma família indígena, hoje a comunidade é constituída por 17 famílias, sendo 30 crianças, 3 adolescentes, 5 jovens e 2 idosos. As crianças da comunidade estudam em escola regular, e os jovens indígenas estão no processo de iniciação do ritual da tucandeira. Sua renda financeira vem dos artesanatos, dos rituais sagrados, e da comidas típicas oferecidas durantes o evento turísticos e visitantes geral.

A cidade de Manaus esta localizada no estado do Amazonas é conhecida também como a grande Manaus.

A cidade pertencente à mesorregião do Centro Amazonense e microrregião de Manaus, localizando-se na confluência dos rios Negro e Solimões. É a maior cidade da Região Norte do Brasil, ocupando uma área de 11.401,058 km² e resultando em uma densidade de 152,50 hab./ $\mathrm{km}^{2}$.

Ocupa uma área de $11.401 \mathrm{~km}^{2}$, representando $0.7258 \%$ do estado do Amazonas, $0.2959 \%$ da Região Norte e $0.1342 \%$ de todo o território brasileiro. Desse total 
229,5040 km² $^{2}$ estão em perímetro urbano. Sua população foi estimada em 2011 pelo IBGE em 1832426 habitantes, sendo assim o 7ํㅡㄴ município mais populoso do Brasil.

$\mathrm{Na}$ cidade de Manaus a vegetação densa, clima variável e tipicamente influenciada pela floresta Amazônica. O município apresenta um relevo caracterizado por planícies, terras firmes, igapós e baixos planaltos, sendo que a altitude média é inferior a 100 metros. O clima é considerado tropical úmido (tipo Af segundo Köppen).

Manaus dividi-se em sete regiões: norte, sul, centro-sul, oeste, centro-oeste e a rural.A maioria da população encontra-se nas zonas leste e norte da cidade, sendo a Cidade Nova ( Zona Norte ) o bairro mais populoso, com mais de 250 mil moradores. A regiao metroplolitana de Manaus ( RMM ) possui 1.814.489 habitantes ( IBGE 2007 ).

\subsection{SUJEITOS DA PESQUISA}

Os sujeitos da pesquisa foram o tuxaua (Moisés Sateré, depois substituído pelo tuxaua Nilson Sateré) e os moradores da comunidade Y'apyrehyty, na cidade de Manaus. Para tanto foram realizadas visitas ao barracão da comunidade Y'apyrehyty durante o processo do trabalho de campo da pesquisa, em Manaus.

\subsection{PROCEDIMENTOS METODOLÓGICOS}

Como procedimento metodológico para estabelecer a aproximação e compreensão da realidade foi utilizada a observação participante que consiste uma interação sociocultural e familiarização com a comunidade e a entrevista semi-estruturada por meio do diálogo informal com os moradores indígenas para o aprofundamento da caracterização das manifestações artístico-culturais do Povo Sateré-Mawé vivendo em contexto intercultural na área urbana de Manaus. Foi realizado um o registro o áudio visual dos processos constituintes do ritual da tucandeira dos adultos e jovens da comunidade Sateré-Mawé Yapyrehyt. Após a coleta de dados foi desenvolvida a análise dos dados na perspectiva de interpretação e compreensão dos significados das informações obtidas. 
A finalidade da análise de dados consistiu em estabelecer uma compreensão dos dados coletados, confirmar ou não os pressupostos da pesquisa e/ ou responder às questões formuladas, e ampliar o conhecimento sobre o assunto pesquisado articulando-o ao contexto cultural da qual faz parte. Para apresentação e discussão dos resultados foi elaborado o relatório final para sistematização da pesquisa com o intuito de formulação de um artigo possibilitando maior divulgação e fomentando questionamentos e discussões coletivas para maior diálogo crítico entre o conhecimento tradicional e o científico.

\section{CONSIDERAÇÕES FINAIS}

A história, a tradição e a cultura do povo Sateré-Mawé, têm sido expostas oralmente, através de narrativas contadas pelos sábios, que transmitem seus conhecimentos e experiências culturais passando de geração a geração. $\mathrm{Na}$ contemporaneidade é responsabilidade dos jovens cultivarem esses saberes a fim de fortalecer e valorizar as práticas sociais da vida cotidiana e as manifestações artísticoculturais do Povo Sateré-Mawé no futuro.

Nesse sentido, corrobora a ideia de Levis-Strauss (1976) quando cometemos o erro de crer que o selvagem é exclusivamente governado por suas necessidades orgânicas ou econômicas, não reparamos que eles nos dirigem a mesma censura, e que, a seus olhos seu próprio desejo de saber parece melhor equilibrado que o nosso.

Desta forma, Percebe-se que os indígenas possuem capacidades de criar e recriar seus conhecimentos tradicionais mesmo fora de seu ambiente tradicional e de manifestar as suas expressões artístico-culturais por meio da dança tradicional do Ritual da Tucandeira e da produção do artesanato com o uso de recursos naturais classificados de acordo com sua classificação tradicional.

\section{REFERÊNCIAS}

BREGOLATO, Roseli Aparecida. Cultura Corporal da Dança. Livro do Professor e do Aluno. São Paulo-SP: Ícone Editora Ltda. 2000. 
LEFF, Henrique,( coord ): tradução de Elite Wolf. A complexidade ambiental. São Paulo: Cortez 2003.

LÉVI-STRAUSS, Claude. O pensamento Selvagem. 2.ed. Campinas: Papirus, 1997.

MINAYO, Maria Cecília de Souza. O desafio do conhecimento. São Paulo-Rio de Janeiro: HUCITEC-ABRASCO, 1994.

PORTAL AMAZÔNIA. Historia de Manaus. Disponível em: www.portalamazonia.com.br/secao/amazoniadeaz/interna.php?id >Acesso em 15 de Julho de 2012.

PORTINARI, Maribel. História da Dança. Rio de Janeiro: Nova floresta, 1989.

TEIXEIRA, Pery.(et all). Sateré-Mawé: Retrato de um povo indígena. Manaus: UFAM/FEPI/SEDUC/COIAB, 2005.

VIANNA, Klauss. A Dança. São Paulo: 2008. Summus Editorial. 